\title{
Tumour necrosis factor gene polymorphisms and childhood wheezing
}

\author{
H. Bilolikar*,\#, A.R. Nam ${ }^{+}$, M. Rosenthal*, J.C. Davies*, \\ D.C. Henderson" and I.M. Balfour-Lynn*,\#
}

ABSTRACT: Tumour necrosis factor (TNF)- $\alpha$ is associated with childhood wheezing. A genetic predisposition to increased TNF-a production, influenced by single nucleotide gene polymorphisms, may be important.

Frequencies of TNF- $\alpha-308 G / A$ and lymphotoxin (LT)- $\alpha+252 G / A$ polymorphisms were compared in 115 asthmatic children, 55 wheezy infants and 156 control school children from the UK. Genotype frequencies for the TNF- $\alpha-308$ and LT- $\alpha+252$ polymorphisms were significantly different from controls.

Haplotype analysis showed that TNF- $\alpha-308 G$, LT- $\alpha+252 A / T N F-\alpha-308 A$, LT- $\alpha+252 A$ was associated with a markedly increased risk for both asthma and infant wheezing. The TNF- $\alpha-308 G$, LT$\alpha+252 G / T N F-\alpha-308 G$, LT- $\alpha+252$ A combination was protective for asthma and infant wheezing. These findings were confirmed by analysis of Caucasian data. Nasal TNF- $\alpha$ levels were measured in the infants during acute wheezing episodes and higher, but nonsignificant levels were produced in those with one or two LT-a+252A alleles. Unexpectedly, significantly lower nasal TNF$\alpha$ levels were found in the presence of one or two TNF- $\alpha-308$ A alleles. TNF- $\alpha-308 / L T-\alpha+252$ genotype combinations had a significant influence on nasal TNF- $\alpha$ levels.

In conclusion, these findings may have implications for future early intervention studies by helping to identify infants at increased risk for wheezing and childhood asthma.

KEYWORDS: Asthma, genetics, paediatric, tumour necrosis factor- $\alpha$

I $t$ is well established that airway inflammation is of paramount importance in the pathophysiology of asthma and infant wheezing, and in particular during viral-induced episodes [1]. Some children mount an exaggerated inflammatory response and it is possible that they are genetically predisposed to do so. A number of cytokines participate in the inflammatory cascade, however, the amount of each produced is quite variable amongst individuals. One example is tumour necrosis factor (TNF)- $\alpha$, which is a proinflammatory cytokine that has been implicated in both asthma [2] and respiratory viral infections [1]. In one study, nasal TNF- $\alpha$ levels were significantly increased in infants during acute, wheezy episodes associated with respiratory tract infections, but levels varied as much as 400 -fold between individuals [3]. Furthermore, in vitro work has shown marked inter-individual differences in TNF- $\alpha$ production by peripheral blood mononuclear cells taken from healthy subjects, however the production in the same subject was highly reproducible [4].

The TNF- $\alpha$ gene is located within the class III region of the major histocompatibility complex
(MHC) close to the HLA-B locus on chromosome $6 \mathrm{p}$. A polymorphism in the promoter region of the TNF- $\alpha$ gene at nucleotide -308 , relative to the transcription start site, may be important in determining the host $\mathrm{TNF}-\alpha$ response [5]. It is important to note that although traditionally this polymorphism is said to be at the -308 position, it has since been pointed out that there was an initial misnumbering and this polymorphism is in fact sited at nucleotide -307 , relative to the transcription start site $[6,7]$. However, most of the literature has stuck to the 308 nomenclature, as have the current authors for the sake of clarity. There are two alleles at the polymorphic site, TNF- $\alpha-308 \mathrm{G}$ (TNF1) and TNF- $\alpha-308 \mathrm{~A}$ (TNF2). In normal populations, TNF- $\alpha-308 \mathrm{G}$ homozygosity is the tried to determine whether the polymorphism influences TNF- $\alpha$ expression or susceptibility to certain diseases. Results are conflicting, but a recent review suggested that the TNF- $\alpha-308 \mathrm{G} / \mathrm{A}$ polymorphism does have a small, but significant, functional effect, with the A allele being associated with higher constitutive and inducible levels of transcription for TNF- $\alpha$ than the G allele [7]. predominant genotype. A number of studies have
AFFILIATIONS

*Dept of Paediatric Respiratory Medicine, Royal Brompton Hospital,

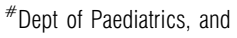
"Dept of Immunology, Chelsea \& Westminster Hospital, and +Dept Clinical Immunology, Hammersmith Hospital, London, UK.

CORRESPONDENCE I.M. Balfour-Lynn Dept of Paediatric Respiratory Medicine

Royal Brompton \& Harefield NHS Trust Sydney Street London SW3 6NP UK Fax: 442073518763 E-mail: i.balfourlynn@ic.ac.uk

Received:

June 152004

Accepted after revision: June 082005

\section{SUPPORT STATEMENT}

This study was supported by funding from the Chelsea and Westminster Hospital Special Trustees, London, UK. 
Within the TNF gene complex, in the first intron of the lymphotoxin $\alpha$ (LT- $\alpha$; TNF- $\beta$ ) gene, there is an NcoI restriction polymorphism. This is known as $\operatorname{TNFB}^{*} 1$, or $\operatorname{LTB}^{*} 1$, in the presence of the restriction site and $\mathrm{TNFB}^{*} 2$, or $\mathrm{LTB}^{*} 2$, in its absence [8]. In strong linkage disequilibrium with the $\mathrm{TNFB}^{*} 1$ and $\mathrm{TNFB}^{*} 2$ alleles there is a second variant, a noncoding G/A polymorphism, at position +252 after the transcription initiation site, known as LT- $\alpha+252$. LT- $\alpha+252 \mathrm{G}$ corresponds to $\mathrm{TNFB}^{*} 1$, and $\mathrm{LT}-\alpha+252 \mathrm{~A}$ corresponds to $\mathrm{TNFB}^{*} 2$ [9]. Again, studies on the functional effect of this polymorphism are conflicting, with TNF- $\alpha$ expression said to be either increased in association with $\mathrm{TNFB}^{*} 2[8,10]$ or not associated with it [9].

There have been numerous studies into disease associations with these TNF polymorphisms, which have been summarised by HAUKIM et al. [11]. As regards their association with respiratory disease, the TNF- $\alpha-308 \mathrm{~A}$ allele (either in the homozygous or heterozygous state) has been found to be associated with an increased risk of developing chronic bronchitis in adults [12], and with increased disease severity in children with cystic fibrosis [13]. Work in asthma in various ethnic groups has, so far, produced conflicting results with studies showing an association with TNF- $\alpha-308 \mathrm{~A}$ [14-19] and TNF- $\alpha-308 G[20,21]$, or none at all with the TNF- $\alpha-308$ locus [22-28]; with LTB*1 $[14,15], \mathrm{LTB}^{*} 2[20,29]$ or none with the LT$\alpha$ locus $[18,22,23,25,29-31]$. The aim of the present study was to investigate the genetics of TNF- $\alpha$ production in terms of the TNF- $\alpha-308$ and LT- $\alpha+252$ alleles, and their relationship to childhood asthma and infant wheezing. In addition, in the wheezy infants, a novel attempt was made to relate the genotype to the functional phenotype, namely nasal TNF- $\alpha$ levels measured during an acute wheezing episode.

\section{METHODS}

\section{Subjects}

Asthmatic children aged between 2-17 yrs were recruited from respiratory clinics in two London hospitals 1 mile apart. Clinical diagnosis of asthma had been confirmed in all subjects by the same respiratory paediatrician. The subjects were subclassified as: 1) severe asthma if they were taking $\geqslant 800$ mcg. day ${ }^{-1}$ inhaled corticosteroids (beclomethasone/budesonide equivalent dose), or 2) mild/moderate asthma if taking

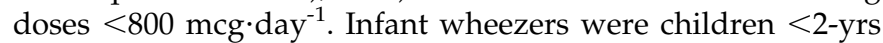
old admitted to one of the hospitals with an acute wheezing illness. Normal controls were children aged $>8$ yrs who were attending one of four local schools ( $<1$ mile away) and who had no doctor-diagnosis of asthma.

\section{Sampling}

DNA was collected from all subjects using CEP buccal swabs (Life Technologies Ltd., Paisley, Scotland) to gently scrape the inside of the mouth. Nasal lavage was performed on the wheezy infant group using a previously described method, whereby $2 \mathrm{~mL}$ phosphate buffered saline, at room temperature, was instilled into each nostril while simultaneously aspirating the fluid back from the anterior nares using a soft rubber Jaques catheter [32]. Inulin $\left(0.45 \mathrm{~g} \cdot \mathrm{L}^{-1}\right)$ was added to the nasal wash as a marker of dilution so that nasal TNF- $\alpha$ levels could be expressed in $\mathrm{pg} \cdot \mathrm{mL}^{-1}$ nasal lining fluid [32]. The wheezy infants also had nasopharyngeal aspirate collected using standard methods for detection of respiratory syncytial virus (RSV), as part of the normal clinical management.

\section{Cytokine polymorphism analysis}

Genomic DNA was extracted from buccal swabs using $20 \%$ chelex 100 , incubated at $56^{\circ} \mathrm{C}$ for $4 \mathrm{~h}$, boiled for $8 \mathrm{~min}$ and then centrifuged at $13,000 \times g$. DNA was stored at $-20^{\circ} \mathrm{C}$. Cytokine polymorphisms in genomic DNA were analysed using PCR with sequence specific primers (SSP). The primers and protocols used were based on those described by PERREY et al. [33]. The primers were designed to be of $\sim 20$ base pairs (bp) in length containing the known polymorphisms at the $3^{\prime}$ end, in order to yield a product between $250-300 \mathrm{bp}$ and to be of similar $G$ and $C$ content to ensure efficient priming. Human growth hormone was used as internal control for the PCRSSP. Following PCR amplification, the products were size separated by electrophoresis $(280 \mathrm{~V}$ for $20 \mathrm{~min}$ ) on a $2 \%$ agarose gel. The PCR products were stained with ethidium bromide $\left(0.5 \mathrm{mg} \cdot \mathrm{mL}^{-1}\right)$ and visualised by ultraviolet chemiluminescence.

\section{Nasal tumour necrosis factor-a}

The nasal lavage fluid was centrifuged at 3,000 $\times g$ for $20 \mathrm{~min}$, within 10 min of collection, and stored at $-80^{\circ} \mathrm{C}$. Nasal TNF- $\alpha$ was measured in the supernatant by ELISA, using a commercial Quantikine Human TNF- $\alpha$ immunoassay kit (R\&D Systems Europe Ltd, Abingdon, UK). Manufacturers' instructions were carried out and the lower limit of detection was $20 \mathrm{pg} \cdot \mathrm{mL}^{-1}$. Inulin was measured by spectrophotometry using an adaptation of the method described by HEYROVSKY [34].

\section{Respiratory syncytial virus}

Identification of RSV was determined by standard direct immunofluorescence and viral culture.

\section{Statistics}

Allele frequency was calculated as follows:

$[(2 \times$ homozgotes $)+(1 \times$ heterozygotes $)] \div 2 \times$ all patients

Hardy-Weinberg equilibrium was calculated for genotypes in the controls using the standard equation with a Chi-squared goodness-of-fit test. The comparison of allele and genotype frequencies between patient groups, and the case control odds ratios (OR) with the 99\% confidence intervals (CI), were calculated using the Chi-squared test with Yates's correction. Haplotype analysis was performed on PHASE software V2.1 (www.stat.washington.edu/stephens) using the $-\mathrm{C}$ and F0 flags with the best pair (0) output for haplotype determination. This programme implements a Bayesian statistical method for reconstructing haplotypes from population genotype data [35, 36]. Bayes' theorem was applied as per AltmAN [37]. Nasal TNF- $\alpha$ levels were compared between patient groups and controls using nonparametric analysis, Mann-Whitney U-tests and Kruskal-Wallis tests since data were not normally distributed. Values of $\mathrm{p}<0.01$ were considered statistically significant, with $99 \%$ CI used as a compromise between multiple contrasts producing spurious statistical associations and missing clinically-relevant associations. Power studies were performed in advance. Assuming a background homozygosity rate of $7 \%$ for TNF- $\alpha-308 \mathrm{~A}$, to detect a $20 \%$ prevalence in 
a study group with an $85 \%$ certainty at the $5 \%$ significance level, required a total cohort of 240 subjects.

\section{RESULTS}

\section{Subjects}

In total, 115 asthmatic children ( 88 mild/moderate, 27 severe), 55 infant wheezers and 156 controls were enrolled. In the study, as expected, there were age differences between the subject groups, but there was no difference in sex (table 1).

\section{Tumour necrosis factor gene polymorphisms}

Polymorphism data for TNF- $\alpha-308$ were unavailable on $7 \%$ wheezing children and $4 \%$ controls, and for LT- $\alpha+252$ on $12 \%$ wheezing children and 5\% controls. Missing data were due to technical reasons relating to DNA extraction or failed PCR.

Allele frequencies for TNF- $\alpha-308 \mathrm{G} / \mathrm{A}$ were not significantly different for either asthmatics or infant wheezers compared with controls $(p=0.04)$. The allele frequencies for LT- $\alpha+252 \mathrm{G} /$ A were not significantly different for asthmatics $(p=0.04)$, but were for infant wheezers $(p<0.01)$ (table 2$)$. There were no differences when comparing severe with mild/moderate asthma.

Genotype frequencies for the TNF- $\alpha-308$ polymorphism for asthmatics and infant wheezers were significantly different from controls ( $p<0.001$; table 3 ; fig. 1$)$. Severe asthma was not

\section{TABLE 1 Subject's characteristics}

Subjects n Mean age yrs Young males Caucasian

\begin{tabular}{lcccc}
\hline Asthma & 115 & $7.7(2-17)$ & 60 & 73 \\
Mild/moderate & 88 & $6.1(2-17)$ & 59 & 74 \\
Severe & 27 & $12.8(4-16)$ & 63 & 70 \\
Infant wheezers & 55 & $6.5(1-20){ }^{\#}$ & 64 & 62 \\
Controls & 156 & $10.2(8-12)$ & 49 & 54 \\
\hline
\end{tabular}

Data are presented as mean (range) or \%, unless otherwise stated. ${ }^{\#}$ : age in months.

\begin{tabular}{lccc} 
TABLE 2 & Allele frequencies & & \\
\multicolumn{1}{l}{ Controls } & Asthma & Wheezy infants \\
\hline TNF- $\boldsymbol{\alpha - 3 0 8}$ & & & \\
Subjects n & 149 & 108 & 50 \\
G & 79 & $70^{\#}$ & $65^{\#}$ \\
A & 21 & $30^{\#}$ & $35^{\#}$ \\
LT- $\boldsymbol{\alpha}+\mathbf{2 5 2}$ & 148 & & 48 \\
Subjects n & 59 & 101 & $34^{\star *}$ \\
G & 41 & $47^{\#}$ & $66^{\star *}$ \\
A & & $53^{\#}$ & \\
\hline
\end{tabular}

Data are presented as per cent unless otherwise stated. TNF- $\alpha-308$ : tumour necrosis factor- $\alpha-308$ genotype; LT- $\alpha+252$ : Iymphotoxin- $\alpha+252$ genotype; $\#$ : $\mathrm{p}=0.04 ;{ }^{* *}: \mathrm{p}<0.01$. $\mathrm{p}$-values reflect the whole ratio compared to controls.

\begin{tabular}{|c|c|c|c|}
\hline & Controls & Asthma & Wheezy infants \\
\hline \multicolumn{4}{|l|}{ TNF- $\alpha-308$} \\
\hline Subjects n & 149 & 108 & 50 \\
\hline GG & 63 & $46^{\star \star \star}$ & $34^{\star \star \star}$ \\
\hline GA & 31 & $47^{\star \star \star}$ & $62^{\star \star \star}$ \\
\hline AA & 6 & $7 * \star \star$ & $4^{\star \star \star}$ \\
\hline \multicolumn{4}{|l|}{ LT- $\alpha+252$} \\
\hline Subjects $n$ & 148 & 101 & 48 \\
\hline $\mathrm{GG}$ & 33 & $33^{\star \star \star}$ & $10^{\star \star \star}$ \\
\hline GA & 51 & $29 * \star *$ & $48^{\star * \star}$ \\
\hline $\mathrm{AA}$ & 16 & $39 * \star \star$ & $42^{\star \star \star}$ \\
\hline
\end{tabular}

Data are presented per cent unless otherwise stated. TNF- $\alpha-308$ : tumour necrosis factor- $\alpha-308$ genotype; LT- $\alpha+252$ : Iymphotoxin- $\alpha+252$ genotype. *** $p<0.001$, $p$-values reflect the whole ratio compared to controls.

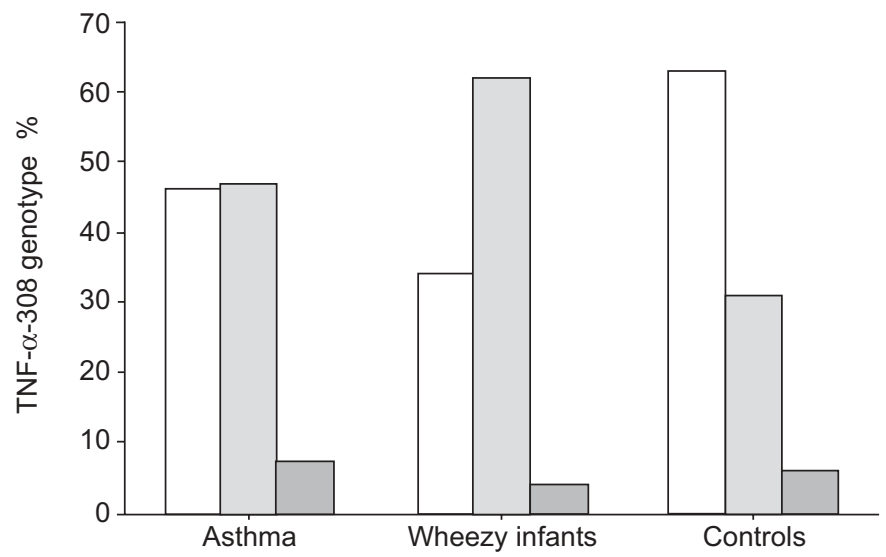

FIGURE 1. Genotype frequencies (\%) for tumour necrosis factor (TNF)- $\alpha-308$ polymorphisms in asthma $(n=108)$, wheezing infants $(n=50)$ and controls $(n=149)$. Frequencies were significantly different from controls $(p<0.001) . \square: G G ; \quad \square$ : GA; 10: AA.

different from mild/moderate asthma. The genotype frequencies for LT- $\alpha+252$ polymorphism showed that asthmatics and infant wheezers were significantly different from the controls $(\mathrm{p}<0.001)$, and again severe asthma was not different from mild/moderate asthma (table 3; fig. 2). Genotype distributions were found to be in Hardy-Weinberg equilibrium in the controls. Linkage disequalibrium (LD) was calculated and there was evidence of LD between the two loci studied, with a $\mathrm{D}$ prime of 0.5 in the subjects and controls (subgroup analysis revealed D prime to be $0.31,0.52$ and 0.88 for asthmatics, wheezy infants and controls, respectively).

Haplotype analysis using a permutation test demonstrated significant differences in haplotype frequencies between asthmatics, wheezy infants and controls, with a global p-value of $<0.01$ in both the whole sample and Caucasians only (table 4).

In terms of individual haplotypes (table 5), the largest effect was seen with the combination TNF- $\alpha-308 \mathrm{G}, \mathrm{LT}-\alpha+252 \mathrm{~A} /$ 


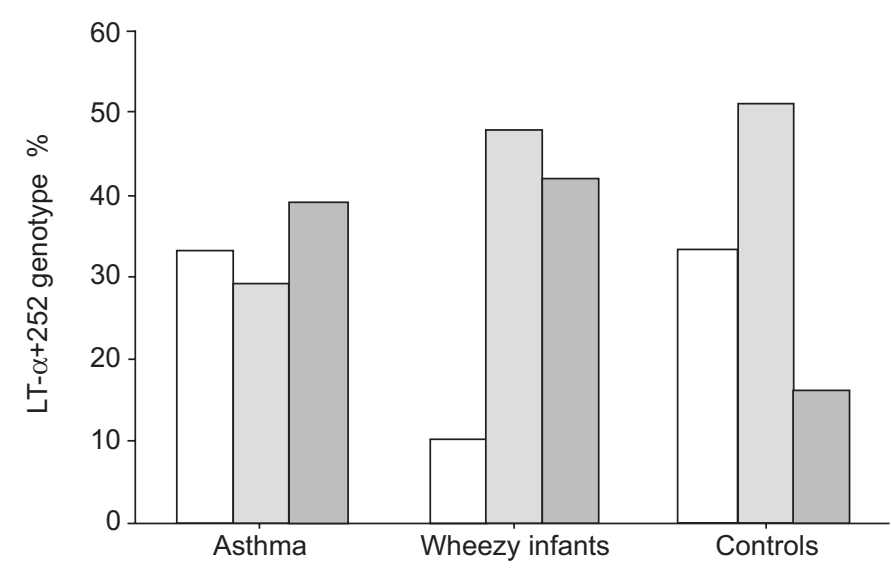

FIGURE 2. Genotype frequencies (\%) for lymphotoxin (LT)- $\alpha+252$ polymorphism in asthma $(n=101)$, wheezing infants $(n=48)$ and controls $(n=148)$. Frequencies were significantly different from controls $(p<0.001)$. $\square$ : GG; $\square$ : GA; 1ः: AA.

\begin{tabular}{|c|c|c|c|c|}
\hline TABLE 4 & $\begin{array}{l}\text { Haplotyk } \\
\text { differenc } \\
\text { asthmat }\end{array}$ & $\begin{array}{l}\text { analysis de } \\
* \star \text { in haplot } \\
\text { wheezy inf }\end{array}$ & $\begin{array}{l}\text { onstrating } \\
\text { oe frequenc } \\
\text { nts and con }\end{array}$ & $\begin{array}{l}\text { ynificant } \\
\text { ols between } \\
\text { ols }\end{array}$ \\
\hline Haplotype & & Controls & Asthma & $\begin{array}{l}\text { Wheezy } \\
\text { Infants }\end{array}$ \\
\hline \multicolumn{5}{|c|}{ TNF- $\alpha-308 \mathrm{~A}, \mathrm{LT}-\alpha+252 \mathrm{G}$} \\
\hline All & & $19(17-21)$ & $20(18-22)$ & $21(17-25)$ \\
\hline Caucasian & & $22(19-25)$ & $21(18-24)$ & $25(19-31)$ \\
\hline \multicolumn{5}{|c|}{ TNF- $\alpha-308 A$, LT- $\alpha+252 A$} \\
\hline All & & $2.6(0.6-4.4)$ & $11(9-13)$ & $14(9.5-18.5)$ \\
\hline Caucasian & & $3.1(0.4-5.8)$ & $12(9.5-14.5)$ & $13(7-19)$ \\
\hline \multicolumn{5}{|c|}{ TNF- $\alpha-308 G, L T-\alpha+252 G$} \\
\hline All & & $40(38-42)$ & $27(24-30)$ & $14(10-18)$ \\
\hline Caucasian & & $37(34-40)$ & 25 (22-29) & $15(9-22)$ \\
\hline \multicolumn{5}{|c|}{ TNF- $\alpha-308 G, L T-\alpha+252 A$} \\
\hline All & & $39(37-41)$ & $42(39-45)$ & $51(47-55)$ \\
\hline Caucasian & & $39(36-42)$ & $43(40-46)$ & $46(40-52)$ \\
\hline
\end{tabular}

Data are presented as per cent mean (95\% confidence interval). TNF- $\alpha-308$ : tumour necrosis factor- $\alpha-308$ genotype. LT- $\alpha+252$ : lymphotoxin- $\alpha+252$ genotype. ${ }^{* *}: p<0.01$

TNF- $\alpha-308 \mathrm{~A}$, LT- $\alpha+252 \mathrm{~A}$, where there was a markedly increased OR for both asthma (OR: 13.7; 99\% CI: 2-94) and infant wheezing (OR: 12.5; 99\% CI: 2-103) compared with controls. Haplotype analysis of TNF- $\alpha-308 \mathrm{G}$, LT- $\alpha+252 \mathrm{~A} / \mathrm{TNF}-\alpha-308 \mathrm{~A}$, LT $-\alpha+252 \mathrm{~A}$ for the risk of asthma or infant wheezing had a high specificity $(100 \%)$, but a low sensitivity $(17 \%)$ with a positive predictive value (PPV) of $100 \%$ and a negative predictive value (NPV) of 54\%. Using Bayes' theorem and assuming a disease prevalence of $30 \%$ for both conditions in the general population, the overall PPV for disease, given the gene profile, was $100 \%$ and the NPV 74\%. Assuming 20\% disease prevalence, the PPV remained $100 \%$ whilst the NPV increased to $82 \%$.

Introducing an LT- $\alpha+252 \mathrm{G}$ allele (to produce TNF- $\alpha-308 \mathrm{G}$, LT- $\alpha+252 \mathrm{~A} / \mathrm{TNF}-\alpha-308 \mathrm{~A}$, LT- $\alpha+252 \mathrm{G})$ counterbalanced the wheeze-promoting effect of TNF- $\alpha-308 \mathrm{G}, \mathrm{LT}-\alpha+252 \mathrm{~A} / \mathrm{TNF}-\alpha-$ 308A, LT- $\alpha+252 \mathrm{~A}$ leading to a nonsignificant OR for asthma. Although, there was still a significant effect on wheezy infants (OR: 3.0; 99\% CI: 1.2-7.6). The introduction of a further second TNF- $\alpha-308$ G allele (TNF- $\alpha-308$ G, LT- $\alpha+252 \mathrm{G} / \mathrm{TNF}-\alpha-308 \mathrm{G}$, LT$\alpha+252 \mathrm{~A})$ had an even greater counterbalance. This produced a protective effect with a reduced OR for asthma of $0.3(99 \% \mathrm{CI}$ : $0.1-0.7)$ and infant wheezing of 0.2 (99\% CI: 0.04-0.7). For some of the combinations, numbers were too small to make valid comparisons.

Individual haplotypes with significant ORs were then analysed using data for Caucasian subjects only. The previous positive findings were confirmed in this subgroup (table 6).

\section{Nasal tumour necrosis factor-a}

In total, there were 55 infant wheezers who each had a nasal lavage. Of which, 32 were RSV-positive and 23 RSV-negative. There was no age difference between the two groups (median 5 versus 6 months, respectively). Nasal TNF- $\alpha$ levels were not significantly affected by RSV status, with median (interquartile ranges) of 697 (424-2187) in the RSV-positive infants versus 359 (101-1176) $\mathrm{pg} \cdot \mathrm{mL}^{-1}$ nasal lining fluid in the RSV-negative infants $(\mathrm{p}=0.12)$.

Data on TNF- $\alpha-308$ polymorphisms were only available on 50 out of the total 55 infant wheezers and LT- $\alpha+252$ on 48 out of 55 for technical reasons. Nasal TNF- $\alpha$ levels were significantly higher in those with TNF- $\alpha$-308GG genotype compared with TNF- $\alpha-308$ GA ( $p=0.007$; table 7 ; fig. 3 ). There were only two infants with the TNF- $\alpha$-308AA genotype, but combining them with the heterozygotes confirmed that the presence of one or two A alleles led to significantly lower nasal TNF- $\alpha$ levels $(p=0.006)$. There was a trend to higher nasal TNF- $\alpha$ levels in those with the LT- $\alpha+252 \mathrm{GA}$ genotype compared with LT$\alpha+252 \mathrm{GG}(\mathrm{p}=0.07)$, and a trend to higher levels in the presence of one or two A alleles $(\mathrm{p}=0.08)$. However, overall differences were not significant (Kruskal-Wallis $\mathrm{p}=0.16$; fig. 4). Analysing TNF- $\alpha-308 /$ LT- $\alpha+252$ genotype combinations showed that there was a significant influence on nasal TNF- $\alpha$ levels (Kruskal-Wallis $\mathrm{p}=0.007$; fig. 5).

\section{DISCUSSION}

A definite relationship was found between two single nucleotide gene polymorphisms in the TNF gene complex and childhood wheezing in a mixed UK population. In keeping with some [14-19], but not all [20-26, 28] studies, TNF- $\alpha-308 \mathrm{~A}$ was associated with childhood asthma. It was also found to be associated with infant wheezing. The only other study to look at this young age group found, in contrast, that TNF- $\alpha-308 \mathrm{~A}$ was not a risk factor for the development of asthma by 12 months of age in 373 Canadian infants from atopic families [27]. The reason for this variance may relate to the fact that only 12 out of $281(4 \%)$ of their infants were labelled as having "probable asthma". Therefore, the numbers are rather small for significant differences to be found. In addition, ZHU et al. [27] mislabelled the $G$ and A alleles in their paper. There is a marked increase in the proportion of TNF- $\alpha-308 \mathrm{GA}$ in the wheezy infants (with a corresponding deficit of GG). Although the current authors have no explanation for this finding, it is believed to be a genuine (biological) rather than genotyping error. Laboratory analysis of cases and controls were mixed 
TABLE 5 Inferred haplotype comparing asthma and infant wheezing with controls in the entire study group

\begin{tabular}{|c|c|c|c|c|c|}
\hline & \multirow{2}{*}{$\begin{array}{c}\text { Controls } \\
\text { n (\%) }\end{array}$} & \multicolumn{2}{|c|}{ Asthma } & \multicolumn{2}{|c|}{ Wheezy infants } \\
\hline & & n (\%) & OR $(99 \% \mathrm{Cl})$ & n (\%) & OR $(99 \% \mathrm{Cl})$ \\
\hline TNF- $\alpha-308 G$, LT- $\alpha+252 G / T N F-\alpha-308 G, L T-\alpha+252 G$ & 19 (13) & 11 (11) & NS & $0(0)$ & NS \\
\hline TNF- $\alpha-308 G$, LT- $\alpha+252 G / T N F-\alpha-308 G, L T-\alpha+252 A$ & $52(35)$ & $13(13)$ & $0.3(0.1-0.7)$ & $4(8)$ & $0.2(0.04-0.7)$ \\
\hline TNF- $\alpha-308 G$, LT- $\alpha+252 A / T N F-\alpha-308 G$, LT- $\alpha+252 A$ & $23(16)$ & $21(21)$ & NS & $13(27)$ & NS \\
\hline TNF- $\alpha-308 G$, LT- $\alpha+252 A / T N F-\alpha-308 A$, LT- $\alpha+252 A$ & $0(0)^{\#}$ & $16(16)$ & $13.7(2-94)$ & $7(15)$ & $12.5(2-103)$ \\
\hline TNF- $\alpha-308$ A, LT- $\alpha+252 G / T N F-\alpha-308 A$, LT- $\alpha+252 G$ & $7(5)$ & $6(6)$ & NS & $0(0)$ & NS \\
\hline TNF- $\alpha-308 A, L T-\alpha+252 G / T N F-\alpha-308 A, L T-\alpha+252 A$ & $2(1)$ & $2(2)$ & NS & $2(4)$ & NS \\
\hline TNF- $\alpha-308$ A, LT- $\alpha+252 A / T N F-\alpha-308$ A, LT- $\alpha+252 A$ & $0(0)$ & $0(0)$ & NS & $0(0)$ & NS \\
\hline Total & 148 & 101 & & 48 & \\
\hline
\end{tabular}

Data are presented as $n(\%)$ or odds ratio (OR) to control (99\% confidence interval: Cl). NS: nonsignificant; TNF- $\alpha-308$ : tumour necrosis factor- $\alpha-308$ genotype; LT- $\alpha+252$ : lymphotoxin- $\alpha+252$ genotype. ${ }^{*}$ : For this haplotype, the OR was calculated nominating $\mathrm{n}=2$ for the control as this represents the approximate upper $95 \% \mathrm{Cl}$ for zero; it is substituted for zero so that an OR may be calculated in a conservative manner, otherwise when $\mathrm{n}=0$ an $\mathrm{OR}$ of infinity is produced.

TABLE 6 Inferred haplotype comparing asthma and infant wheezing with controls in Caucasians

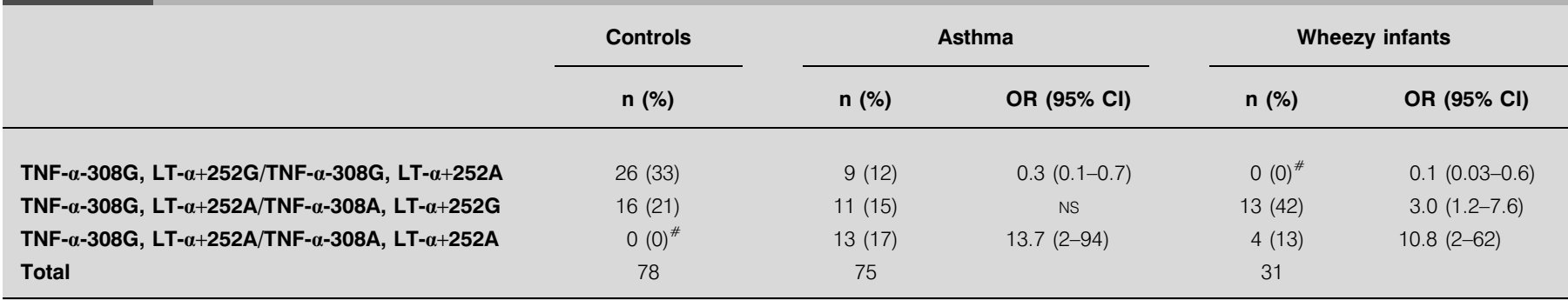

Data are presented as $n(\%)$ or odds ratio $(\mathrm{OR})$ with $95 \%$ confidence intervals $(95 \% \mathrm{Cl})$. This data shows the comparison of comparing asthma and infant wheezing with controls in white Caucasians depending on tumour necrosis factor- $\alpha-308$ genotype (TNF- $\alpha-308$ )/lymphotoxin- $\alpha+252$ genotype (LT- $\alpha+252$ ) haplotype analysis. Analysis only performed in the three significant haplotype shown from table 5. Ns: nonsignificant. ${ }^{*}$ : For these haplotypes, the OR was calculated nominating $n=2$ for the control as this represents the approximate upper $95 \% \mathrm{Cl}$ for zero; it is substituted for zero so that an OR may be calculated in a conservative manner, otherwise when $\mathrm{n}=0$ an OR of infinity is produced.

TABLE 7 Nasal tumour necrosis factor- $\alpha$ levels in wheezing infants related to TNF gene polymorphisms

\section{Subjects $n \quad$ Nasal TNF- $\alpha$ pg $\cdot \mathrm{mL}^{-1}$ nasal lining fluid}

$\begin{array}{lcc}\text { TNF- } \boldsymbol{\alpha}-\mathbf{3 0 8} & & \\ \text { GG } & 17 & 1435(620-2667) \\ \text { GA } & 31 & 469(122-964) \\ \text { AA } & 2 & 555 \\ \text { LT- } \boldsymbol{\alpha}+\mathbf{2 5 2} & & \\ \text { GG } & 5 & 431(46-564) \\ \text { GA } & 23 & 796(423-2212) \\ \text { AA } & 20 & 604(159-1911)\end{array}$

Data presented as median (interquartile range), unless otherwise stated. TNF: tumour necrosis factor- $\alpha$; TNF- $\alpha-308$ : TNF- $\alpha-308$ genotype; LT- $\alpha+252$ : lymphotoxin- $\alpha+252$ genotype. Levels were significantly higher in TNF- $\alpha-308 G G$ than TNF- $\alpha$-308GA $(p=0.007)$, but other differences were nonsignificant. together (blinded) and the present figures for controls match previously published work. Therefore, if there had been a systematic genotyping error, control data would also have been expected to be abnormal as well, which was not the case. However, these data do need to be repeated as the number of wheezy infants analysed was relatively small.

The current authors found that LT- $\alpha+252 \mathrm{~A}$ was associated with asthma. This was found to be in keeping with previous studies which investigated the equivalent $\mathrm{TNFB}^{* 2}[20,29]$, but again there are others studies which have found either the reverse $[14,15]$ or no association at all $[18,22,23,25,28-31]$. Haplotype analysis showed one particular combination (TNF- $\alpha-308 \mathrm{G}$, LT$\alpha+252 \mathrm{~A} / \mathrm{TNF}-\alpha-308 \mathrm{~A}, \mathrm{LT}-\alpha+252 \mathrm{~A}$ ) led to a markedly increased risk for both asthma and infant wheezing, although with wide $99 \%$ CI. It is important to note that the admittedly unexpected high $\mathrm{OR}$, and consequent wide $\mathrm{CI}$, represents a conservative estimate as no control child actually had this gene combination, which would, therefore, give an OR of infinity. Therefore, two control children were allocated this haplotype, representing the upper $95 \%$ CI for 0 out of 148 . Introducing an 


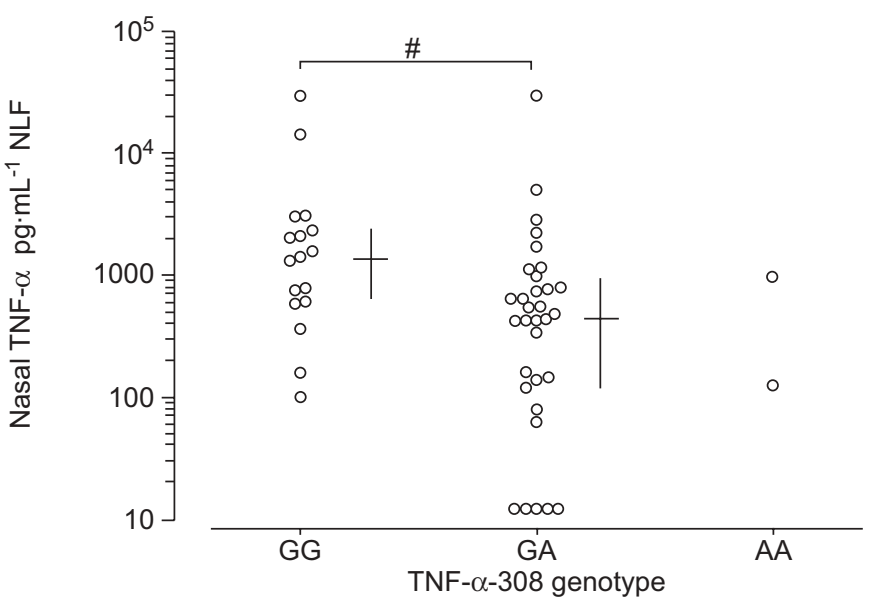

FIGURE 3. Nasal tumour necrosis factor (TNF)- $\alpha$ levels $\left(\mathrm{pg} \cdot \mathrm{mL}^{-1}\right.$ nasal lining fluid: NLF) related to TNF- $\alpha-308$ genotype in wheezing infants $(n=50)$. Levels were significantly higher in TNF- $\alpha-308 \mathrm{GG}$ compared with the TNF- $\alpha$-308GA genotype $(p=0.007)$. The $y$-axis is a logarithmic scale. The horizontal line represents the median, and the vertical line represents the interquartile range, for each group of data. ${ }^{*}: p=0.007$.

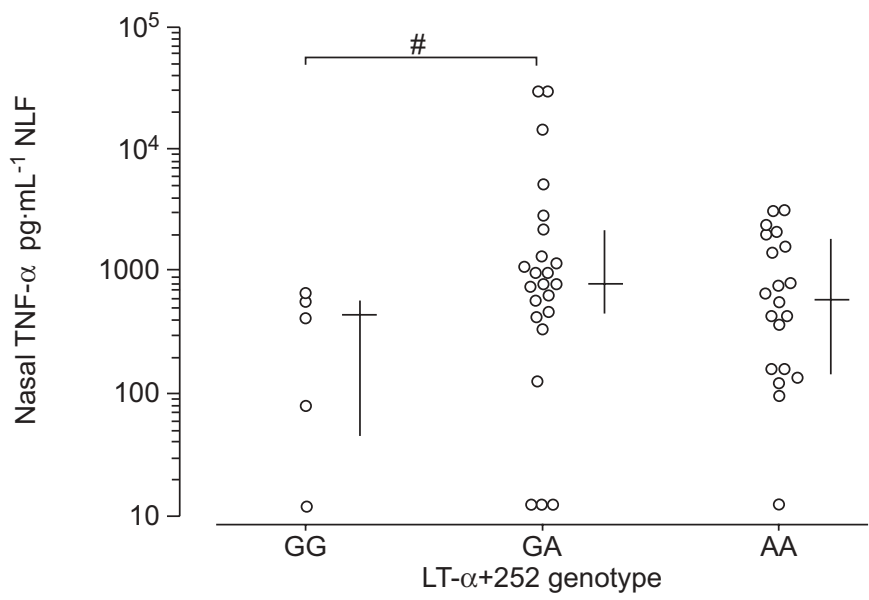

FIGURE 4. Nasal tumour necrosis factor (TNF)- $\alpha$ levels $\left(\mathrm{pg} \cdot \mathrm{mL}^{-1}\right.$ nasal lining fluid: NLF) related to lymphotoxin (LT)- $\alpha+252$ genotype in wheezing infants $(n=48)$. The $y$-axis is a logarithmic scale. The horizontal line represents the median, and the vertical line represents the interquartile range, for each group of data. ${ }^{*}: p=0.07$. Differences were not statistically significant (Kruskal-Wallis $p=0.16$ ), although there was a trend to lower levels in $L T-\alpha+252 G G$ compared with the $L T-\alpha+252 G A$ genotype $(p=0.07)$

LT- $\alpha+252 \mathrm{G}$ allele had a counterbalancing effect, which was further enhanced by the introduction of a second TNF- $\alpha-308 \mathrm{G}$ allele, so that the TNF- $\alpha-308 \mathrm{G}$, LT- $\alpha+252 \mathrm{G} / \mathrm{TNF}-\alpha-308 \mathrm{G}$, LT$\alpha+252$ A combination was actually protective for both asthma and infant wheezing.

Two grades of asthma severity were studied (mild/moderate versus severe), using a deliberately simple definition based on daily requirement of inhaled corticosteroids. The cut-off used was $800 \mathrm{mcg} \cdot \mathrm{day}^{-1}$ of beclomethasone equivalent, as this is the one used by the European Respiratory Society Task Force on difficult or therapy-resistant asthma [38]. Neither allele nor

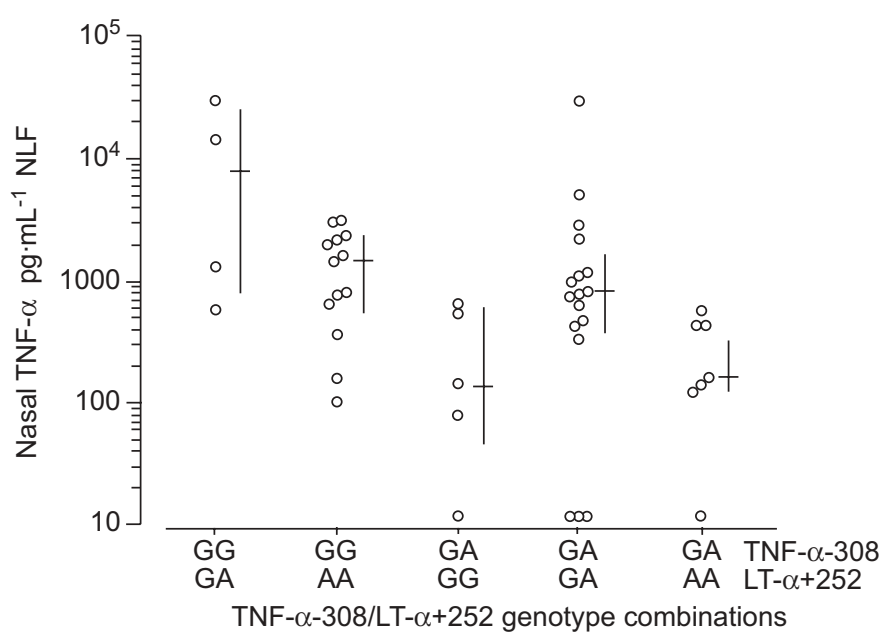

FIGURE 5. Nasal tumour necrosis factor (TNF)- $\alpha$ levels $\left(\mathrm{pg} \cdot \mathrm{mL}^{-1}\right.$ nasal lining fluid: NLF) related to TNF- $\alpha-308 /$ lymphotoxin (LT)- $\alpha+252$ genotype combinations in wheezing infants $(n=46)$. The horizontal line represents the median, and the vertical line represents the interquartile range, for each group of data. TNF- $\alpha$ levels were significantly different for the various combinations (Kruskal-Wallis $p=0.007$ ). The $y$-axis is a logarithmic scale.

genotype frequencies were different between the two groups, although the TNF- $\alpha$-308AA genotype did seem to be more common in the severe asthmatics $(12 \%)$ compared with mild/ moderate asthma or controls ( 5 and $6 \%$, respectively). CHAGANI et al. [16] found that the TNF- $\alpha-308 \mathrm{~A}$ polymorphism was not significantly more prevalent in 159 adults with fatal or near fatal asthma compared with 92 with mild or moderate asthma. LOUIS et al. [26] also found no association with asthma severity (as measured by lung function) in 193 adults. It is perhaps not surprising that the severity of asthma is not associated with these TNF gene polymorphisms given the multiple complex factors that determine the severity of disease in any individual [39]. However, firm conclusions cannot be drawn from the current study as it was only adequately powered for "all asthma" and not the subgroups.

There are contrasting findings reported in some of the published asthma studies, and there are a number of potential reasons for the discrepancies. The nomenclature used for TNF gene polymorphisms is complicated, and mistakes in the literature further confuse the picture [27, 40, 41]. Many problems arise from study design faults and some of the pitfalls of candidate gene association studies have been detailed in the excellent critique by HALL [42]. Underpowered studies are a cause for concern as the lack of an association, or a false positive one, may simply be due to a type II or I error rather than a genuine finding. A study on replication validity of genetic association studies showed that those with $<150$ cases were less likely to be replicated subsequently [43], although many of the asthma studies reporting no association seem adequately powered, given the known allele frequency of the polymorphisms being tested. However, one of two studies to report an association between TNF- $\alpha-308 \mathrm{G}$ with asthma was a relatively small one (74 asthmatics, 50 controls), which might account for the 
unexpected finding [20]. The present study was planned around the known allelic frequency of TNF- $\alpha-308 \mathrm{G} / \mathrm{A}$ in the UK population, and the numbers reached that required for "all asthma", although not for the severity subgroups; the number of wheezy infants analysed was also smaller than ideal. The controls used can be a problem and it is important to ensure the same racial mix is used. In the current study, the subjects and controls were from the same area of London (UK) and racial mix was similar in the groups. However, subgroup analysis was performed on the Caucasian subjects (whose ethnicity is more easily defined), and this confirmed the authors' findings from the whole study group on the effect of haplotypes. Many of the published asthma studies are from quite different population groups, which could account for some of their different findings, as the prevalence of polymorphisms within different racial groups is often markedly different [42]. Comparisons of findings between different ethnic groups may be irrelevant due to population-specific masking of gene variant effects, or gene-environment interactions specific to one population [44]. It is also important to ensure that the control population is appropriately chosen to exclude those with the disease being studied. This can be a problem with questionnaire-based studies with their known recall and bias problems. In the study by WINCHESTER et al. [17], only 20 out of $649(3 \%)$ pregnant UK or Irish females recalled having childhood asthma, which is certainly less than expected. The control school children in the present study were selected on the basis of lack of previous doctor-diagnosed asthma, which although not infallible is likely to be correct, especially in a group of $8-12-y r$ olds. Whilst it is possible some may have undiagnosed asthma, this would not have exaggerated any differences in the results (if anything it leads to underestimates of differences if the controls contained some asthmatics). It is certainly likely that the control population contained some children who had wheezed as infants, but who had outgrown this by 8-yrs of age and, hence, had no current diagnosis of asthma. The only way around this problem would be to conduct lengthy prospective studies. Furthermore, the age differences between the controls and wheezing infants means that any influence of environmental interactions on the asthma genotype could not be assessed due to the crosssectional nature of this study.

Defining the patient population itself can be problematic, the current patient group had a diagnosis based on a single respiratory paediatrician's assessment and is assumed to be correct. A skewed study population was inevitable as the authors set out to enrol wheezy children, thus, the ratio of patients to controls (approximately equal) does not reflect the proportions found naturally in the UK population. This leads to falsely high PPV and NPV (although the sensitivity and specificity remain the same). Hence, Bayes' theorem was employed and factored in the incidence of wheezing in the general population to get a more realistic PPV. The definition of asthma in infancy is even more problematic, so a simple pragmatic approach of enlisting infants with an acute wheezing episode was adopted. The authors decided against attempting to categorise them as infantile asthma or viralassociated wheeze, and preferred not to employ the complicated definition of "probable asthma" as used by ZHU et al. [27] in their 12 month old infants. Undoubtedly some of the wheezy infant group would end up being classified as asthmatic when older.

Another problem with genotype patient studies is that of assessing whether any association found with a disease state is genuine or whether it is due to linkage disequilibrium. This is the phenomenon whereby combinations of alleles occur together more or less often than expected by chance alone, due to their positions relative to each other on the gene. Any association found with a particular polymorphism may then be due to a nearby polymorphism, which is in linkage disequilibrium with the one under scrutiny. There is extensive linkage disequilibrium on chromosome 6 [44]. The TNF- $\alpha$ gene is located within the class III region of the MHC close to the HLA-B locus. The MHC is the most polymorphic region of the genome and there is strong linkage disequilibrium within the MHC itself. The TNF- $\alpha-308 \mathrm{~A}$ allele is strongly associated with the HLA A1, B8 and DR3 alleles [45]. Furthermore, the DR3 and DR4 haplotypes produce higher levels of TNF- $\alpha$ while DR2 is associated with low production [4]. However, secretion of TNF- $\alpha$ has been shown to be elevated in individuals carrying the TNF- $\alpha-308 \mathrm{~A}$ allele regardless of their DR3 status, indicating that linkage to DR3 is not responsible for elevated TNF- $\alpha$ production [46]. It has been suggested that the association of certain MHC haplotypes with TNF- $\alpha$ phenotypes may not be due to polymorphism within the TNF gene itself, but rather to variation of a further linked gene [47]. In this study, it was not possible to assess HLA-DR status in the subjects, making it hard to comment on whether linkage to the $\mathrm{MHC}$ is relevant to the current findings. Although, previous findings showing that LD exists between the two loci studied (TNF- $\alpha-308$ and LT- $\alpha+252)$ was confirmed. However, it was surprising to find disparity between the degrees of linkage disequilibrium in the disease groups tested. This could mean that some of the present results reflect the effects of another, closely related polymorphic locus. Mapping of the flanking areas of theses genes was not performed as part of this study, but could be incorporated into future studies.

One way of determining the relevance of linkage disequilibrium is to study the associations with extended haplotypes [42]. In the study by MOFFATT and COOKSON [14] of 413 Australian subjects from 88 nuclear families, questionnairediagnosed asthma was positively associated with the TNF- $\alpha$ $308 \mathrm{~A}$ allele and also with the LT- $\alpha \mathrm{B}^{*} 1$ allele. Although they found the TNF- $\alpha-308 \mathrm{~A}, \mathrm{LT}-\alpha \mathrm{B}^{*} 1$ and HLA-DRB ${ }^{*} 03$ alleles are in linkage disequilibrium, by studying haplotypes they showed the association with asthma was not due to the HLA-DR locus. In a larger study of $>1,000$ Australian subjects, MofFATT et al. [15] then showed the extended haplotype TNF$\alpha-308 \mathrm{~A} / \mathrm{LT}-\alpha \mathrm{B}^{*} 1 / \mathrm{HLA}-\mathrm{DRB}{ }^{*} 03$ was weakly associated with questionnaire-diagnosed asthma, whilst the rarer TNF- $\alpha$ $308 \mathrm{~A} / \mathrm{LT}-\alpha \mathrm{B}^{*} 1 / \mathrm{HLA}-\mathrm{DRB} 1^{*} 02$ was more strongly associated with asthma and bronchial hyperreactivity. Although the latter haplotype carried a higher risk of asthma, it was rare, so had less impact on the population-attributable risk of asthma. It was difficult to differentiate between the effects of these alleles in this haplotype, but a functional polymorphism contributing to asthma susceptibility is likely to be contained within this haplotype. In a study of 239 asthmatics, an association of asthma with TNF- $\alpha-308$ A/HLA-DRB1*03 was found only in those with positive skin prick testing to Lolium (ryegrass), 
whilst an association with TNF- $\alpha-308$ A/HLA-DRB1*1104 was found only in those sensitive to Parietaria (herb pollen) [48]. DI SOMMA et al. [48] suggested this implied that the association of TNF- $\alpha-308 \mathrm{~A}$ with asthma reflected linkage disequilibrium with genes influencing a specific immune response. Whilst studying haplotype and genotype combinations may give more useful results, if too many polymorphisms are included the subgroups become so numerous that huge patient numbers are required, otherwise statistical evaluation becomes difficult. In the study by MOFFATT et al. [15] that combined three loci (TNF$\alpha-308$, LT- $\alpha$ NcoI and HLA-DRB1), there were 56 possible haplotypes, therefore even with over 1,000 subjects many of the haplotype frequencies were too small to be meaningful.

If a direct functional effect of a polymorphism can be demonstrated, it makes the clinical significance of the polymorphism greater. It also makes it more likely that the polymorphism itself is truly associated with the disease being studied, rather than the association being entirely due to linkage disequilibrium with the true aetiological gene [47]. For this reason nasal TNF- $\alpha$ levels were measured in the wheezy infants, as a marker of the functional phenotype, and related to their genotypes. Although the data did not quite reach statistical significance, due to the relatively low numbers, higher nasal TNF- $\alpha$ levels were found to be produced by those infants with one or two LT- $\alpha+252 \mathrm{~A}$ alleles, during an acute wheezing episode. This is consistent with the finding that the LT $-\alpha+252 \mathrm{~A}$ allele was more common in the wheezing children compared with controls and confirms the LT- $\alpha+252$ locus has some functional significance. It is also consistent with a study on severe sepsis, in which those patients homozygous for TNFB2 (equivalent of LT- $\alpha+252 \mathrm{~A}$ ) had higher plasma levels of TNF- $\alpha$ [49]. By contrast, when the nasal TNF- $\alpha$ levels were related to the TNF- $\alpha-308$ locus, the reverse of that expected was found. Significantly lower nasal TNF- $\alpha$ levels were found in the presence of one or two TNF- $\alpha-308 \mathrm{~A}$ alleles, yet this allele was significantly more common in the wheezing children. In vitro work has also shown this allele to be associated with greater TNF- $\alpha$ production $[7,8,10]$. There is no obvious explanation for this unexpected finding. Nasal TNF- $\alpha$ levels were also influenced by the TNF- $\alpha-308 / \mathrm{LT}-\alpha+252$ genotype combinations. However a recent review by BAYLEY et al. [44], suggested that the TNF- $\alpha$-308GA polymorphism is nonfunctional and has no influence on the activity of the TNF promoter.

Studying gene polymorphisms may aid understanding of the pathophysiology of childhood wheezing, but an overriding question is whether there will be any practical or clinical use for it, and particularly whether it will be useful for an individual child. Most infant wheezers grow out of their condition in early childhood but some will end up diagnosed with genuine asthma. It has been suggested that early intervention with inhaled corticosteroids may prevent the development of asthma [50], but clearly it would be pointless to treat all wheezy infants as in most cases the condition will resolve spontaneously [51]. Therefore, an identifiable marker that would indicate whether an infant is likely to develop genuine asthma would be most useful. Perhaps this is where the study of TNF- $\alpha$ and other gene polymorphisms might have a role. The present study has shown that a haplotype containing TNF- $\alpha-308 \mathrm{~A}$ and LT $-\alpha+252 \mathrm{~A}$ alleles gave the greatest risk for developing asthma, so should all wheezy infants with this genotype receive long-term inhaled corticosteroids? Although specificity was high, the sensitivity was rather low. This means if a child has the relevant genotype, it is quite likely they will develop asthma, but since the particular haplotype is relatively rare, most children with diagnosed asthma will have an alternative genotype. Nevertheless in the presence of the genotype, there might be a case for more aggressive early treatment with corticosteroids. Time and further studies might shed light on this area. Known cohorts could be studied, such as that in Tuscon, in which it is now known which children were "transient wheezers" and which "persistent wheezers" at 6-yrs of age [52]. If such data confirmed the current findings, then the next stage would be a prospective early intervention study on those with the at risk genotype. It would need large numbers to identify sufficient patients with the relevant genotype, and of course there are so many other risk factors that must be taken in to account (for example atopy, passive smoking, pre-existing lung function), that matching groups would be extremely difficult.

In conclusion, it was found that polymorphisms that affected tumour necrosis factor- $\alpha$ production were associated with childhood wheezing, but did not seem related to the severity of asthma. In wheezy infants, nasal tumour necrosis factor- $\alpha$ levels were influenced by the genotype, but not always in the expected direction. Identification of certain high-risk haplotypes may be important for future early intervention studies.

\section{ACKNOWLEDGEMENTS}

The authors would like to thank the children and their parents who participated in this study. They would also like to thank J. Mak from National Heart Lung Institute (London, UK) who helped with the original DNA extraction and M. Howell from Southampton General Hospital (Southampton, UK) for helping I. M. Balfour-Lynn to understand the nomenclature. Finally, they would like to thank Chelsea and Westminster Hospital Special Trustees (London, UK) who funded this study.

\section{REFERENCES}

1 Balfour-Lynn IM, Openshaw P. Viral infection. In: Silverman M, ed. Childhood Asthma and Other Wheezing Disorders. 2nd Edn. London, Arnold, 2002; pp. 205-221.

2 Thomas PS. Tumour necrosis factor- $\alpha$ : The role of multifunctional cytokine in asthma. Immunol Cell Biol 2001; 79: 132-140.

3 Balfour-Lynn IM, Valman HB, Wellings R, Webster ADB, Taylor GW, Silverman M. Tumour necrosis factor- $\alpha$ and leukotriene $\mathrm{E}_{4}$ production in wheezy infants. Clin Exp Allergy 1994; 24: 121-126.

4 Jacob CO, Fronek Z, Lewis GD, Koo M, Hansen A, McDevitt HO. Heritable major histocompatibility complex II-associated differences in production of tumour necrosis factor $\alpha$ : relevance to genetic predisposition to systemic lupus erythematosus. Proc Natl Acad Sci USA 1990; 87: 1233-1237.

5 Kroeger KM, Carville KS, Abraham LJ. The -308 tumour necrosis factor-alpha promoter polymorphism effects transcription. Mol Immunol 1997; 34: 391-399. 
6 Uglialoro AM, Turbay D, Pesavento PA, et al. Identification of three new single nucleotide polymorphisms in the human tumour necrosis factor-alpha gene promoter. Tissue Antigens 1998; 52: 359-367.

7 Allen RD. Polymorphism of the human TNF- $\alpha$ promoter random variation or functional diversity? Mol Immunol 1999; 36: 1017-1027.

8 Rink L, Kirchner H. Recent progress in the tumour necrosis factor- $\alpha$ field. Int Arch Allergy Immunol 1996; 111: 199-209.

9 Messer G, Spengler U, Jung MC, et al. Polymorphic structure of the tumour necrosis factor (TNF) locus: an NcoI polymorphism in the first intron of the human TNFbeta gene correlates with a variant amino acid in position 26 and a reduced level of TNF-beta production. J Exp Med 1991; 173: 209-219.

10 Pociot F, Briant L, Jongeneel CV, et al. Association of tumour necrosis factor (TNF) and class II major histocompatibility complex alleles with the secretion of TNF-alpha and TNF-beta by human mononuclear cells: a possible link to insulin-dependent diabetes mellitus. Eur J Immunol 1993; 23: 224-231.

11 Haukim N, Bidwell JL, Smith AJ, et al. Cytokine gene polymorphism in human disease: on-line databases, Supplement 2. Genes Immun 2002; 3: 313-330.

12 Huang S-L, Su C-H, Chang S-C. Tumour necrosis factor- $\alpha$ gene polymorphism in chronic bronchitis. Am J Resp Crit Care Med 1997; 156: 1436-1469.

13 Hull J. Thomson AH. Contribution of genetic factors other than CFTR to disease severity in cystic fibrosis. Thorax 1998; 58: 1018-1021.

14 Moffatt MO, Cookson WO. Tumour necrosis factor haplotypes and asthma. Hum Mol Genet 1997; 6: 551-554.

15 Moffatt MF, James A, Ryan G, Musk AW, Cookson WO. Extended tumour necrosis factor/HLA-DR haplotypes and asthma in an Australian population sample. Thorax 1999; 54: 757-761.

16 Chagani T, Pare PD, Zhu S, et al. Prevalence of tumour necrosis factor- $\alpha$ and angiotensin converting enzyme polymorphisms in mild/moderate and fatal/near-fatal asthma. Am J Respir Crit Care Med 1999; 160: 278-282.

17 Winchester EC, Millwood IY, Rand L, Penny MA, Kessling AM. Association of the TNF- $\alpha-308$ (G-->A) polymorphism with self-reported history of childhood asthma. Hum Genet 2000; 107: 591-596.

18 Wang TN, Chen WY, Wang TH, Chen CJ, Huang LY, Ko YC. Gene-gene synergistic effect on atopic asthma: tumour necrosis factor-alpha-308 and lymphotoxin-alphaNcoI in Taiwan's children. Clin Exp Allergy 2004; 34: 184-188.

19 Witte JS, Palmer LJ, O'Connor RD, Hopkins PJ, Hall JM. Relation between tumour necrosis factor polymorphism TNFalpha-308 and risk of asthma. Eur J Hum Genet 2002; 10: 82-85.

20 Albuquerque RV, Hayden CM, Palmer LJ, et al. Association of polymorphisms within the tumour necrosis factor (TNF) genes and childhood asthma. Clin Exp Allergy 1998; 28: 578-584.

21 Shin HD, Park BL, Kim LH, et al. Association of tumor necrosis factor polymorphisms with asthma and serum total IgE. Hum Mol Genet 2004; 13: 397-403.
22 Tan EC, Lee BW, Tay AW, Chew FT, Tay AH. Asthma and TNF variants in Chinese and Malays. Allergy 1999; 54: 402-403.

23 Li Kam Wa TC, Mansur AH, Britton J, et al. Association between - 308 tumour necrosis factor promoter polymorphism and bronchial hyperreactivity in asthma. Clin Exp Allergy 1999; 29: 1204-1208.

24 Malerba G, Trabetti E, Patuzzo C, et al. Candidate genes and a genome-wide search in Italian families with atopic asthmatic children. Clin Exp Allergy 1999; 29: Suppl. 4 27-30.

25 Trabetti E, Patuzzo C, Malerba G, et al. Association of a lymphotoxin $\alpha$ gene polymorphism and atopy in Italian families. J Med Genet 1999; 36: 323-325.

26 Louis R, Leyder E, Malaise M, Bartsch P, Louis E. Lack of association between adult asthma and the tumour necrosis factor $\alpha-308$ polymorphism gene. Eur Respir J 2000; 16: 604-608.

27 Zhu S, Chan-Yeung M, Becker AB, et al. Polymorphisms of the IL-4, TNF- $\alpha$, and FceRI $\beta$ genes and the risk of allergic disorders in at-risk infants. Am J Respir Crit Care Med 2000; 161: 1655-1659.

28 Buckova D, Holla LI, Vasku A, Znojil V, Vacha J. Lack of association between atopic asthma and the tumor necrosis factor alpha-308 gene polymorphism in a Czech population. J Investig Allergol Clin Immunol 2002; 12: 192-197.

29 Campbell DA, Li Kam Wa E, Britton J, Holgate ST, Markham AF, Morrison JF. Polymorphism at the tumour necrosis factor locus and asthma. Monogr Allergy 1996; 33: 125-137.

30 Noguchi E, Yokouchi Y, Shibasaki M, et al. Association between TNFA polymorphism and the development of asthma in the Japanese population. Am J Respir Crit Care Med 2002; 166: 43-46.

31 van Hage-Hamsten $M$, Johansson E, Kronqvist $M$, Loughry A, Cookson WO, Moffatt MF. Associations of FceR1- $\beta$ polymorphisms with immunoglobin E antibody responses to common inhalant allergens in a rural population. Clin Exp Allergy 2002; 32: 838-842.

32 Balfour-Lynn IM, Valman HB, Silverman M, Webster ADB. Nasal IgA response in wheezy infants. Arch Dis Child 1993. 68: 472-476.

33 Perrey C, Turner SJ, Pravica V, Howell WM, Hutchinson IV. ARMS-PCR methodologies to determine IL-10, TNF- $\alpha$, TNF- $\beta$ and TGF- $\beta 1$ gene polymorphisms Transpl Immunol 1999; 7: 127-128.

34 Heyrovsky A. A new method for the determination of insulin in plasma and urine. Clin Chim Acta 1956; 1 : 470-474.

35 Stephens M, Smith NJ, Donnelly P. A new statistical method for haplotype reconstruction from population data. Am J Hum Genetics 2001; 68: 978-989.

36 Stephens M, Donnelly P. A comparison of Bayesian methods for haplotype reconstruction. Am J Hum Genetics 2003; 73: 1162-1169.

37 Altman DG. Practical statistics for medical research London, Chapman Hall, 1991.

38 Chung KF, Godard P, Adelroth E, et al. Difficult/therapyresistant asthma: the need for an integrated approach to define clinical phenotypes, evaluate risk factors, understand pathophysiology and find novel therapies. ERS 
Taskforce on difficult/therapy-resistant asthma. Eur Respir J 1999; 13: 1198-1208.

39 Payne DNR, Balfour-Lynn IM. Difficult asthma in children: a practical approach. J Asthma 2001; 38: 189-203.

40 Warzocha K, Ribeiro P, Bienvenu J, et al. Genetic polymorphisms in the tumour necrosis factor locus influence non-Hodgkin's lymphoma outcome. Blood 1998; 91: 3574-3581.

41 Sandford AJ, Pare PD. The genetics of asthma. The important questions. Am J Respir Crit Care Med 2000; 161: S202-S206.

42 Hall I. Candidate gene studies in respiratory disease: avoiding the pitfalls. Thorax 2002; 57: 377-378.

43 Ioannidis JPA, Ntzani EE, Trikalinos TA, ContopoulosIoannidis DG. Replication validity of genetic association studies. Nat Genet 2001; 29: 306-309.

44 Bayley JP, Ottenhoff TH, Verweij CL. Is there a future for TNF promoter polymorphisms? Genes Immun 2004; 5: 315-329.

45 Wilson AG, de Vries N, Pociot F, di Giovine FS, van der Putte LB, Duff GW. An allelic polymorphism within the human tumour necrosis factor $\alpha$ promoter region is strongly associated with HLA A1, B8, and DR3 alleles. J Exp Med 1993; 177: 557-560.
46 Bouma G, Crusius JB, Oudkerk Pool M, et al. Secretion of tumour necrosis factor $\alpha$ and lymphotoxin $\alpha$ in relation to polymorphisms in the TNF genes and HLA-DR alleles. Relevance for inflammatory bowel disease. Scand J Immunol 1996; 43: 456-463.

47 Wilson AG, Symons JA, McDowell TL, McDevitt HO, Duff GW. Effects of a polymorphism in the human tumour necrosis factor $\alpha$ promoter on transcriptional activation. Proc Natl Acad Sci USA 1997; 94: 3195-3199.

48 Di Somma C, Charron D, Deichmann K, Buono C, Ruffilli A. Atopic asthma and TNF-308 alleles: linkage disequilibrium and association analyses. Hum Immunol 2003; 64: 359-365.

49 Stüber F, Petersen M, Bokelmann F, Schade U. A genomic polymorphism within the tumour necrosis factor locus influences plasma tumour necrosis factor- $\alpha$ concentrations and outcome of patients with severe sepsis. Crit Care Med 1996; 24: 381-384.

50 Pedersen S. Early use of inhaled steroids in children with asthma. Clin Exp Allergy 1997; 27: 995-999.

51 Warner JO. The down-side of early intervention with inhaled corticosteroids. Clin Exp Allergy 1997; 27: 999-1001.

52 Martinez FD. What have we learned from the Tucson Children's Respiratory Study? Paediatr Respir Rev 2002; 3: 193-197. 